\title{
Historicidade da propriedade privada capitalista e os cercamentos
}

\author{
Historicity of capitalist private property and surroundings
}

Historicidad de la propriedade privada capitalista y los cercamentos

Diogo de Calasans Melo Andrade

\section{Resumo}

O objetivo desse artigo é diferenciar os diversos tipos de "propriedade privada" que surgiram em nossa história, desde a Idade Antiga, passando pela Idade Média, até chegar a atual propriedade privada capitalista. Para tanto, identificou-se a relação entre a Revolução Francesa e a Revolução Agrária com surgimento da propriedade privada capitalista. Por outro viés, detectou-se que com as expropriações, decorrentes dos cercamentos, houve a dissolução entre trabalho e propriedade. Com isso, promoveu-se o acúmulo de capital e a expulsão da população do campo para a cidade. Por fim, percebeu-se que esse fenômeno, de origem inglesa, ainda existe, atualmente, impedindo o acesso à terra e empurrando a população pobre para a periferia das cidades.

Palavras-chave: Cercamentos. Origem. Propriedade privada capitalista.

\section{Introdução}

O presente artigo busca fazer um esforço histórico - uma vez que o estudo da história serve para compreender o presente e interferir na construção do futuro - para levantar a tese que a propriedade privada capitalista está diretamente vinculada à sociabilidade capitalista.

A "propriedade privada" na Idade Antiga e o processo de troca interna desenvolveram-se, em um primeiro momento, no Direito Romano, contudo, muito diferente da propriedade privada capitalista atual, pois a propriedade privada romana era comum (comunal) e não uma mercadoria, haja vista que somente após o capitalismo, com o surgimento da propriedade privada burguesa,

Doutor em Direito pela Mackenzie. Pesquisador e professor da Universidade Tiradentes. E-mail: contato@diogocalasans.com

\footnotetext{
Recebido em 26/2/2018 - Aprovado em 31/3/2018 http://dx.doi.org/10.5335/hdtv.18n.3.8597
} 
a propriedade tornar-se-ia mercadoria no processo de troca.

Já a "propriedade privada" feudal, presente na Idade Média, teve seu fundamento na lealdade, pois era do senhor, mas usada pelo vassalo, ou seja, a propriedade não era considerada mercadoria, não podia ser trocada como na sociedade capitalista.

Mas, foi a Revolução Francesa que aboliu a "propriedade privada" feudal instituindo-se a propriedade privada capitalista. A partir da revolução agrária e da monopolização de terras e, por meio do direito burguês, a propriedade privada capitalista tornou-se absoluta e exclusiva, elevada ao patamar de direito absoluto, estável, protegida em todo o mundo pelas leis, pela polícia e pelos tribunais.

De outro modo, com a expropriação e/ ou os cercamentos, passou-se a separar os camponeses dos seus meios de produção, especificamente, a terra, havendo uma dissolução entre o trabalho e a propriedade, pois antes a propriedade era do trabalhador, passando o proprietário a não necessitar trabalhar e a explorar o trabalho do trabalhador. Assim, pretende-se, neste artigo, analisar a ligação entre os cercamentos e a propriedade privada capitalista, como também sua relação com as expropriações atuais.

Desta maneira, somente após o surgimento do capitalismo, pode-se falar em propriedade privada nos moldes atuais, uma vez que a "propriedade privada" feudal foi transformada em propriedade privada capitalista, tornando-se mercadoria e podendo ser negociada.

\section{A propriedade privada individual capitalista e a vitória da burguesia}

Foi a Revolução Francesa que aboliu a "propriedade privada" feudal em favor da burguesia, instituindo a propriedade privada capitalista. Essa revolução estava ligada às lutas dos camponeses do século XVIII, fruto da crise do sistema feudal que existia na época.

Com a revolução burguesa, institui-se uma revolução agrária que transforma as propriedades feudais em propriedades privadas capitalistas, criando-se, assim, a monopolização da terra. Assim, a estrutura da sociedade capitalista proveio da estrutura econômica da sociedade feudal, a decomposição dessa liberou os elementos daquela, explica Marx:

O produtor direito, o trabalhador, somente pôde dispor de sua pessoa depois de estar desvinculado à gleba e de ser servo ou dependente de outra pessoa. Para tornar-se livre vendedor de força de trabalho, que leva sua mercadoria a qualquer lugar onde houver mercado para ela, ele precisa ainda ter escapado do domínio das corporações, de seus regulamentos para aprendizes e oficiais e das prescrições restritivas do trabalho (1996, p. 341).

Os artigos de Marx sobre o furto de madeira $^{1}$ são a primeira incursão de Marx nas controvérsias, que naquele momento chegavam ao auge, sobre a definição propriedade, neles Marx afirma que a Revolução Francesa sacralizou constitucionalmente a propriedade: 
considerada, dentro do espírito liberal revolucionário, o fundamento e a garantia da liberdade individual do cidadão, e a dessacralizou em seguida, tornando oponível a ela o direito à existência, em especial no momento em que se estabeleceu um teto máximo para o preço do pão e dos produtos de primeira necessidade, imposto sob a ascensão dos sans-culottes no Ano II (2017, p. 37).

A propriedade privada capitalista ou burguesa desvinculou-se das anteriores ideias de propriedade privada que existiam para inserir um sentido de utilidade econômica ao bem. Com a revolução burguesa, criou-se uma revolução agrária que está ligada à produção de mercadorias e à proletarização, uma vez que transformou a propriedade feudal em propriedade burguesa. A respeito do abandono da posse fundiária, de seu caráter feudal, para assumir um caráter industrial, com o objetivo de ganhar dinheiro, o filósofo adverte:

A grande posse fundiária, como vemos na Inglaterra, já abandonou o seu caráter feudal e assumiu um caráter industrial, na medida em que quer fazer o máximo dinheiro possível. Ela proporciona ao proprietário a máxima renda fundiária possível, ao arrendatário o máximo lucro possível de seu capital. Os trabalhadores agrícolas estão, por isso, reduzidos já ao mínimo e a classe dos arrendatários já representa o poder da indústria e do capital no interior da posse fundiária (MARX, 2004, p. 77).

Após a Revolução Francesa, o Código de Napoleão, promulgado em 20 de março de 1804, é considerado revolucionário, pois trouxe os ideais burgueses de propriedade, reconhecidos e aplicáveis a serviço da burguesia, constituindo-se uma visível traição aos interesses e às aspirações dos trabalha- dores e camponeses que haviam formado as tropas de choque da Revolução. A propriedade era considerada lei imutável por serem inspiradas por Deus. Entre 1789 e 1800 a nobreza possuía cerca de 25 por cento da terra arável na França, e a maior parte delas passou às mãos da burguesia que passou a deter $30 \%$ do total. Abolindo os interesses feudais nas propriedades imobiliárias, a burguesia garantiu seus empréstimos à velha nobreza e à Coroa e lançou bases de seu poder futuro (TIGAR, 1977, p. 229-242).

Para Hobsbawm (1996, p. 127) felizmente, a Revolução Francesa está viva, pois Liberdade, Igualdade e Fraternidade e os valores da razão e do Iluminismo, os valores que construíram a civilização moderna desde os tempos da Revolução Americana, são mais necessários do que nunca, na medida em que o irracionalismo, a religião fundamentalista, o obscurantismo e a barbárie estão, mais uma vez, avançando entre nós.

Sobre a Revolução Francesa (século XVIII), a abolição da propriedade feudal em benefício da burguesia e os objetivos no comunismo explica Marx:

A Revolução Francesa, por exemplo, aboliu a propriedade feudal em benefício da burguesia.

O que caracteriza o comunismo não é a abolição da propriedade em geral, mas a abolição da propriedade burguesa.

Porém, a moderna propriedade burguesa é a última e mais completa expressão da produção e apropriação de produtos baseadas em antagonismos de classes, na exploração de umas pelas outras.

Nesse sentido, os comunistas podem resumir sua teoria em uma expressão: supressão da propriedade privada $(2015$, p. 48$)$. 
Marx não defendia o fim da propriedade em geral, mas a abolição da propriedade privada nos meios de produção. O significado da propriedade jurídica da terra para Marx é que o proprietário fundiário ${ }^{2}$ pode dispor de sua terra do mesmo modo que qualquer possuidor de mercadorias pode dispor de suas mercadorias. É o capitalismo que transforma a propriedade fundiária feudal em propriedade fundiária moderna quando liberta totalmente das relações de domínio e servidão (PACHUKANIS, 1988, p. 69).

$\mathrm{O}$ direito burguês, segundo o modelo do Código Napoleão, concebeu a propriedade como poder absoluto e exclusivo sobre coisa determinada, visando à utilidade exclusiva do seu titular. Por outro viés, a civilização burguesa estabeleceu a nítida separação entre o Estado e a sociedade civil, entre o homem privado, como indivíduo, e o cidadão, como sujeito da sociedade política. Nesse esquema dicotômico, a propriedade foi colocada inteiramente no campo do direito privado e essa dicotomia foi o alvo preferido da crítica socialista (COMPARATO, 1997, p. 4-5).

Como foi visto, a revolução agrária aboliu a propriedade feudal e instituiu a propriedade privada capitalista, instituindo a monopolização da terra, assim, a propriedade fundiária feudal foi transformada em propriedade fundiária moderna quando ficou livre as relações de domínio e servidão tão presentes da Idade Antiga e Média. Por isso, somente com o direito burguês, a propriedade passou a ser considerada como poder absoluto e exclusivo sobre a coisa determinada, como também se passou a separar o Estado da sociedade civil.

Assim, a propriedade burguesa capitalista deixa de ser uma posse flutuante e instável, uma posse puramente de fato, pas- sível de ser contestada a todo momento e de ser defendida a mão armada para transformar-se em um direito absoluto, estável, que segue a coisa por todo lado e que, desde que a civilização burguesa espalhou seu domínio a todo o globo, é protegida em todo o mundo pelas leis, pela polícia e pelos tribunais (PACHUKANIS, 1988, p. 73).

Marx em seus manuscritos datados de 1844, considerado como seu primeiro texto sobre a questão da propriedade privada, considera a essência subjetiva e objetiva da propriedade privada:

A essência subjetiva da propriedade privada, a propriedade privada como atividade para si, como sujeito, como pessoa, é o trabalho. $[\ldots]$

Mas o trabalho, a essência subjetiva da propriedade privada como exclusão da propriedade, e o capital, trabalho objetivo como exclusão do trabalho, é a propriedade privada como relação desenvolvida da contradição e por isso uma relação enérgica que tende à solução. [...]

[...] a essência subjetiva da propriedade privada [o trabalhador] aparece como exclusão da propriedade [o produto que pertence ao burguês]. E, o capital, como trabalho objetivo [o produto que pertence ao burguês] como exclusão do trabalho [o trabalhador sem propriedade] (2004, p. 99-103).

Comentando essa essência da subjetiva da propriedade (trabalho/ trabalhador), como também da objetiva (o capital/o produto) de Marx, discorre Meksenas:

O conceito de propriedade privada é entendido por Marx dentro de dupla determinação: 1) a essência subjetiva e 2) a essência objetiva. Quando admitimos uma essência subjetiva percebemos que a propriedade privada tem um início, uma força criadora e que se manifesta no sujeito-em-atividade produzindo-a, o trabalho. [...] 
O reconhecimento do estado exterior da propriedade privada é a sua objetividade como propriedade ou como produto de posse; o objeto possuído. Daí que, o trabalho é o em si da propriedade privada e está, o por si. Marx admitiu, ainda, que a descoberta da essência subjetiva da propriedade privada [o trabalho], em época que se reconhecia apenas a sua existência objetiva [o produto], coube a Adam Smith. [...]

Em outras palavras, a sociedade burguesa instituiu historicamente a separação entre quem realiza o trabalho e quem domina a produção deste trabalho; cindiu a essência subjetiva da propriedade privada [o trabalhador] da sua essência objetiva [o produto, que pertence ao burguês] (2008, p. 1, grifos do autor).

Assim, quando Marx trata da essência subjetiva da propriedade, analisa-se o sujeito trabalhador que produz o trabalho, ou seja, sujeito em atividade produzindo-a, o trabalho. Já a essência objetiva da propriedade é o reconhecimento do estado exterior da propriedade, criando o produto da posse, o objeto possuído, qual seja, o capital. Foi a burguesia que separou aquele que realiza o trabalho (o trabalhador) daquele que é dono da produção, do produto (o burguês).

$\mathrm{Na}$ verdade, segundo o autor francês Emmanuel Hérichon, Marx não define um único conceito de propriedade privada, mas criou uma teoria da propriedade:

Assim, recusando-se a "dar uma definição de propriedade como um produto independente, uma categoria separada, uma ideia abstrata e eterna", Marx não deu uma definição de propriedade, mas várias definições. É entender o conceito na diversidade de significados que a história lhe dá, que foi possível identificar uma teoria da propriedade, teoria que não é uma definição, mas a teoria várias definições da propriedade das relações que existem entre cada uma delas ${ }^{3}$ (1970, p. 164).
Ainda sobre os manuscritos de Marx, não é a propriedade privada em sua existência imediata, em seu ser, o fundamento da relação de alienação, mas exatamente o contrário, é o trabalho em sua forma alienada (aqui ainda não há a distinção entre trabalho e força de trabalho) que é a determinação central e originária. A propriedade privada aparece então, não mais em seu modo de ser imediato como pura exterioridade, mas, antes, como oriunda de uma dada relação social que lhe é anterior na ordem do ser. É a atividade, e suas condições subjetivas, transformada em objeto de cessão a outrem que fornece o segredo da propriedade privada (ALVES, 2008, p. 10).

Em sua obra mais importante, $\mathrm{O} \mathrm{Ca}$ pital, Marx trata em seu capítulo XXIV, da acumulação primitiva, ${ }^{4}$ buscando os fatores fundamentais que ocasionaram a transformação do modo de produção feudal para o capitalista, tendo a Inglaterra como objeto de sua investigação. Inicialmente, é necessário compreender o capitalismo e analisar o modo de produção ${ }^{5}$, entendendo como um conjunto de relações de produção entre classes que se transforma em outra, ou seja, trabalhadores camponeses, sem o modo de produção terra, transformam-se em trabalhadores assalariados da indústria.

De mais a mais, quando o antigo obstáculo da propriedade suprema da gens e da tribo foi suprimido pelo novo proprietário, rompe-se o vínculo do proprietário com o solo, surgindo o dinheiro e a propriedade privada da terra, pois a terra agora podia tornar-se mercadoria, podia ser vendida ou penhorada e hipotecada. Com isso, progrediram, rapidamente, a centralização e con- 
centração das riquezas nas mãos de uma classe pouco numerosa e o empobrecimento das massas (ENGELS, 2012, p. 161-162).

Com o fim do feudalismo, o trabalhador torna-se livre e liberto para vender sua força de trabalho. Sobre a liberdade e a igualdade assegura Naves:

As categorias da liberdade e da igualdade estão intimamente relacionadas a esse processo de expropriação da massa camponesa, que é arrancada do ambiente em que vive e produz, despojada dos meios que permitem a sua subsistência e colocada à disposição dos agentes que controlam as condições de produção. A separação do trabalhador direto dos meios de produção vai constituir uma esfera de circulação mercantil inteiramente nova, na qual a própria pessoa ingressa como "portador" de um objeto que é ele mesmo e no qual ele se vende a outro sem perder a liberdade (2014, p. 46).

Marx demonstra que não há nada mais desigual do que o tratamento igual dos desiguais; que a igualdade pressuposta no mercado nos ilude, fazendo acreditar na igualdade entre as pessoas; que as doutrinas burguesas dos direitos de propriedade privada fazem parecer que todos temos direitos humanos; que as ilusões da liberdade pessoal e da liberdade nascem do mercado e do livre comércio (HARVEY, 2013, p. 291).

No Brasil, o primeiro passo para fazer com que o trabalhador livre aceitasse, sob o pretexto da igualdade jurídica, a realidade da desigualdade econômica foi:
Em 1850, quando cessa quase completamente o tráfico negreiro (dificultando o abastecimento das fazendas com a mão de obra escrava), a mesma elite fundiária obtém a aprovação da Lei. n. 601, conhecida como Lei de Terras, que impedia o acesso às terras devolutas por outro meio que não fosse a compra. A Lei de Terras garantiu a mobilização das instituições jurídicas e policiais na defesa da propriedade fundiária, garantindo, ao mesmo tempo, o caráter compulsório do trabalho, da venda da força de trabalho ao fazendeiro por parte dos trabalhadores que não dispusessem de outro meio de viver senão a sua capacidade de trabalhar. Ora, a "riqueza" da época, para os desprovidos de meios, era principalmente a terra, neste país ainda carente de grandes capitais. A Lei das Terras consagrava aquilo que não existia plenamente: a terra como equivalente de capital, como renda territorial capitalizada (MARTINS, 2015, p. 278-279).

Marx defende que a suposta libertação dos produtores das estruturas feudais não significou o fim da exploração, mas o surgimento de uma nova forma de exploração, qual seja, a expropriação (separação do camponês de seus meios de produção, qual seja, a terra), ocorrendo à dissolução entre trabalhador e propriedade. E Marx descreve, com precisão, o processo que cria a relação-capital e o início do avanço do capitalismo:

Portanto, o processo que cria a relação-capital não pode ser outra coisa que o processo de separação de trabalhador da propriedade das condições de seu trabalho, um processo que transforma, por um lado, os meios sociais de subsistência e de produção em capital, por outro, os produtores diretos em trabalhadores assalariados. [...]

O prelúdio do revolucionamento, que criou a base do modo de produção capitalista, ocorreu no último terço do século XV e nas primeiras décadas do século XVI. Uma massa de proletários livres como os pássaros foi lançada no mercado de trabalho pela dissolução dos séquitos feudais [...] (1996, p. 328- 331). 
A propriedade privada capitalista é a sustentação do modo de produção capitalista. Antes a propriedade era do trabalhador, com a transformação em propriedade privada capitalista, o proprietário não trabalha, mas explora o trabalho do trabalhador.

\section{Os antigos cercamentos e as novas expropriações no mundo capitalista}

Os cercamentos das áreas agrícolas dos pequenos proprietários de terra da Inglaterra abarcaram a própria lei no veículo do roubo das terras do povo em favor da burguesia, assim assevera o, talvez, mais importante pensador acerca da história da economia política:

A forma parlamentar do roubo é a das Bills for Inclosuresofommons (leis para o cercamento da terra comunal), em outras palavras, decretos pelos quais os senhores fundiários fazem presente a si mesmos da terra do povo, como propriedade privada, decretos de expropriação do povo. Sir F. M. Eden refuta sua astuta argumentação de advogado, na qual ele busca apresentar a propriedade comunal como propriedade privada dos grandes proprietários fundiários, que tomaram o lugar dos feudais, ao pedir ele mesmo "uma lei parlamentar geral para o cercamento das terras comunais", admitindo, portanto, que é necessário um golpe de Estado parlamentar para sua transformação em propriedade privada, porém, por outro lado, solicitando da legislatura uma "indenização" para os pobres expropriados (MARX, 1996, p. 348349 , grifos do autor).

Assim, com a expropriação existiu a separação do camponês dos seus meios de produção, qual seja a terra. Com isso, houve a dissolução entre trabalho e proprieda- de. Antes a propriedade era do trabalhador, após a propriedade capitalista, o proprietário não trabalha, mas explora o trabalho do trabalhador.

Por isso, os produtores rurais ficaram impossibilitados de trabalhar em suas terras, tendo que buscar emprego na indústria, aumentando a mão de obra e extraindo a mais-valia. ${ }^{6}$ Marx descreve o surgimento da propriedade privada capitalista, gerada a partir dessa lei que possibilitava cercar as terras comunais, ou seja, um golpe do Estado parlamentar para a transformação da propriedade comunal (terra comuns) em propriedade privada dos grandes proprietários fundiários.

Comentando o roubo sistemático da propriedade comunal e o cercamento das terras comuns, Harvey adverte:

A violenta usurpação dessa propriedade comunal, em geral acompanhada da transformação das terras de lavoura em pastagens, tem início no final do século XV e prossegue durante o século XVI [...]. Marx escolhe um exemplo posterior, o caso espetacular da expulsão dos habitantes das Terras Altas escocesas, onde os camponeses foram expulsos pouco a pouco de suas terras até o fim do século XIX [...]. A questão sobre o que todas essas pessoas expulsas de suas terras fariam... Em geral não havia emprego para elas; então, ao menos aos olhos do Estado, tais indivíduos se tornavam vagabundos, mendigos, ladrões e assaltantes. $\mathrm{O}$ aparato estatal respondia de um modo que perdura até nossos dias: criminalizando e encarcerando, tratando-os como vagabundos e praticando contra eles a mais extrema violência (2013, p. 283).

O cercamento expropriou as terras dos camponeses com o intuito de promover o acúmulo do capital. Outro ponto importan- 
te para o crescimento da propriedade burguesa pela luta pela soberania absoluta foi a expulsão violenta do camponês de sua terra comunal, como por exemplo, o florescimento da manufatura de lã, crescendo a violência dos usurpadores, pois a alta dos preços da lã, fez com que as terras rurais transformassem em pastagens para as ovelhas:

Foi muito mais, em oposição mais teimosa à realeza e ao Parlamento, o grande senhor feudal quem criou um proletariado incomparavelmente maior mediante expulsão violenta do campesinato da base fundiária, sobre a qual possuía o mesmo título jurídico feudal que ele, e usurpação de sua terra comunal. O impulso imediato para isso foi dado, na Inglaterra, nomeadamente pelo florescimento da manufatura flamenga de lã e a consequente alta dos preços da lã (MARX, 1996, p. 331).

O último grande processo de expropriação dos lavradores da base fundiária foi clamado de "Clearing of Estates" (clarear propriedades, de fato, limpá-las de seres humanos). Todos os métodos ingleses até agora observados culminaram no "clarear". $\mathrm{Na}$ Escócia, os celtas da alta constituíam clãs, cada um deles proprietário do solo por ele ocupado. O representante do clã, seu chefe ou "grande homem", era apenas o proprietário titular desse solo, tal como a rainha da Inglaterra é a proprietária titular de todo o solo nacional. Quando o governo inglês conseguiu reprimir as guerras desses "grandes homens" e suas contínuas incursões nas planícies da baixa Escócia, os chefes de clãs não renunciaram, de modo algum, a seu velho ofício de assaltante; mudaram apenas a forma. Por conta própria, transformaram seu direito titular de propriedade em direito de propriedade privada e, como encontraram resistência por parte dos membros do clã, resolveram enxotá-los com violência direta (MARX, 1996, p. 352-353).

Embora a transformação do campo sob o impacto do mercado global de commodities - agrícolas ou de exploração mineral - tenha ampliado a escala da expulsão populacional e impulsado a migração para as cidades, não se trata de um processo novo, ele é conhecido desde as origens do capitalismo, quando os "enclosures of the commons" (cercamento dos espaços comuns) impediram acesso à terra por parte dos antigos servos, empurrando para a proletarização nas cidades (ROLNIK, 2015, p. 159).

Quando o homem, como sujeito individual e parte de um contrato, torna-se a medida das práticas sociais, a propriedade se define em relação a ele como propriedade privada. Contento em si uma dinâmica de expansão de seus campos de aplicação, a noção de propriedade entra em conflito com sua concepção antiga como modo de posse passiva. Assim, somente no século XVIII o movimento de cercamentos (a apropriação de terras comunais pelos grandes proprietários de terra), iniciado na Inglaterra no fim do século $\mathrm{XV}$, recebeu unção legal, foi aí que a própria lei se tornou o instrumento da espoliação (MARX, 2017, p. 24).

O primeiro projeto de lei de cercamento foi aprovado no Parlamento em fevereiro de 1710 e os historiadores têm observado que a grande era dos cercamentos parlamentares, entre 1760 e 1820, comprova não só o frenesi pelo desenvolvimento agrícola, mas, também, a tenacidade em que os sujeitos "impertinentes" e "despeitados" obstruíam 
os cercamentos por acordo, resistindo até o fim em favor da antiga economia baseada nos costumes (THOMPSON, 1998, p. 94-95).

Esses antigos cercamentos de terras ainda existem na atualidade, senão vejamos:

Observa-se, na atualidade, que os "cercamentos", descritos por Marx em sua abordagem do capitalismo nascente na Inglaterra como mecanismos básicos para a acumulação primitiva, não deixaram de atuar como componentes do capitalismo na acumulação avançada. Trata-se do que vem sendo chamado por estudiosos de "novos cercamentos", fenômenos de expropriação observáveis tanto em países pouco desenvolvidos quanto naqueles de desenvolvimento mais avançado (PENHAVEL, 2011, p. 2).

O açambarcamento das terras foi defendido na época em nome da propriedade agrícola, cujo crescimento supostamente erradicaria a fome e a penúria, ainda que à custa de uma terrível miséria humana. Hoje estaríamos presenciando uma nova onda de cercamentos, que se justifica pela corrida à inovação ou pela urgência da alimentação mundial (MARX, 2017, p. 58).

Nos últimos 250 anos da história da relação social entre a humanidade e o território, uma forma específica de uso e direito sobre a terra - a propriedade privada individual - se sobrepôs às demais, esse movimento tem início com o cercamento das terras comunais na Europa do século XVIII, por meio do processo definido como "deslocamento territorial", ou a separação entre terra e trabalho, e avançou em sua direção à sua consagração jurídico-política na construção do Estado liberal, mas, recentemente, passou a se estender sobre o conjunto do planeta, por intermédio da expansão global das formas capitalistas de produção e consumo (ROLNIK, 2015, p. 195).

Assim, com os cercamentos, surgiu a propriedade privada capitalista, transformando a propriedade comunal em privada capitalista, para isso, houve a expropriação das terras do camponês, com o objetivo de acúmulo do capital. Ainda hoje, existem os cercamentos e são denominados de expropriação, presentes tanto nos países pouco desenvolvidos quanto nos de desenvolvimento mais avançado. Com o cercamento, impediram o acesso à terra, empurrando a população para as cidades, ocasionando a proletarização.

Percebe-se, por tudo isso, que os métodos utilizados para a acumulação primitiva de capital e, consequentemente, para o surgimento da propriedade privada capitalista foram os bens roubados da igreja, a venda fraudulenta dos domínios do Estado, o furto da propriedade comunal (terra comum) e a transformação violenta e usurpadora da propriedade feudal em propriedade privada moderna (com os cercamentos das terras). Assim, entendendo a história da transformação da propriedade privada, primeiro em feudal e, for fim, em capitalista, podemos compreender melhor a propriedade privada moderna no sistema capitalista em que vivemos.

Assim, somente após o surgimento do capitalismo a propriedade feudal transforma-se em propriedade privada capitalista, considerada como mercadoria e essencial ao processo de troca. Por outro viés, os proprietários tornam-se sujeito de direito, aptos a contratar, com base na igualdade e na lealdade, podendo vender ou trocar a propriedade privada, surgindo, assim, a subjetividade jurídica. 


\section{Considerações finais}

A partir das teorias e exposições realizadas, observa-se um importante debate sobre a origem da propriedade privada. Nesse sentido, detectou-se que, na Idade Antiga, não existia a propriedade privada capitalista, haja vista que a propriedade privada era comum e não uma mercadoria, uma vez que o proprietário não podia apropriar-se da mercadoria alheia e vender a sua.

Na Idade Média, exista a "propriedade privada" feudal, que não era mercadoria, não podia ser negociada, como desejava a burguesia, uma vez que sua base era a relação feudal de lealdade, entre senhor feudal e servo, com uma dominação fundada na religião e na moral, por isso, pode-se, também, afirmar que não exista a propriedade privada capitalista naquela época.

Identificou-se que foi a Revolução Francesa que aboliu a "propriedade privada" feudal, criando a propriedade privada capitalista, para atender os anseios da burguesia. Com essa revolução, institui-se a revolução agrária, transformando as propriedades privadas feudais em privadas capitalistas, com a possibilidade da monopolização da terra. Aqui não existem mais as relações de domínio e servidão presentes na Idade Antiga e na Idade Média.

Detectou-se que com a expropriação, por meio dos cercamentos das áreas agrícolas da Inglaterra, ocasionou a separação do camponês dos seus meios de produção (a terra), havendo a dissolução entre trabalho e propriedade; antes a propriedade era do trabalhador, após o surgimento da propriedade privada capitalista, o proprietário não trabalha, mas explora o trabalho do trabalhador.

Esse cercamento expropriou as terras dos camponeses com o intuito de promover o acúmulo do capital, impedindo o acesso à terra e empurrando a população do campo para a cidade, sendo um dos motivos para o surgimento da proletarização. Através dos cercamentos surgiu a propriedade privada capitalista e, atualmente, eles ainda existem, mas denominados de novos cercamentos ou expropriações, o que impede o acesso à terra e expulsa a população para as periferias das cidades.

Por isso, conclui-se que somente após o surgimento do capitalismo podemos falar em propriedade privada nos moldes capitalistas atuais, uma vez que a "propriedade privada feudal" foi transformada em propriedade privada capitalista, tornando-se mercadoria e podendo ser negociada, para isso, os proprietários foram considerados sujeitos de direito, "livres e iguais", aptos a contratar e poder comprar ou vender sua propriedade privada capitalista.

\section{Abstract}

The purpose of this article is to differentiate the various types of "private property" that have emerged in our history, from the Old Age, through the Middle Ages, to the present private capitalist property. For this, the relation between the French Revolution and Agrarian Revolution was identified with the emergence of private capitalist property. On the other hand, it was detected that with the expropriations, resulting from the enclosures, there was the dissolution 
between work and property. As a result, capital accumulation and expulsion of the population from the countryside to the city were promoted. Finally, it was realized that this phenomenon, of English origin, still exists today, preventing access to land and pushing the poor population to the periphery of cities.

Keywords: Enclosures. Origin. Private capitalist property.

\section{Resumen}

El objetivo de este artículo es diferenciar los diversos tipos de "propiedad privada" que surgieron en nuestra historia, desde la Edad Antigua, pasando por la Edad Media, hasta llegar a la actual propiedad privada capitalista. Para ello, se identificó la relación entre la Revolución Francesa y la Revolución Agraria con surgimiento de la propiedad privada capitalista. Por otro lado, se detectó que con las expropiaciones, derivadas de los cercamientos, hubo la disolución entre trabajo y propiedad. Con ello, se promovió la acumulación de capital y la expulsión de la población del campo a la ciudad. Por último, se percibió que ese fenómeno, de origen inglés, todavía existe actualmente, impidiendo el acceso a la tierra y empujando a la población pobre hacia la periferia de las ciudades.

\footnotetext{
Palabras clave: Recinto. Origen. Propiedad privada capitalista.
}

\section{Notas}

1 Esses artigos foram transformados em livro, traduzidos para o português e publicado no Brasil sob o título: Os despossuídos: debates sobre a lei referente ao furto de madeira (MARX, 2017).

2 "Ao discutir a renda da terra e a propriedade fundiária em particular, Marx revela a estrutura da formação de valor e preço, o que é crucial para a análise da concorrência. A mais-valia é também apropriada sob outras formas, como a renda da terra, para a qual as relações da propriedade fundiária são importantes, e o juro, razão pela qual o capital financeiro deve ser analisado. A conclusão de Marx é que, na medida em que o acesso do capital à terra é limitado pela propriedade fundiária, o desenvolvimento intensivo da agricultura fica obstruído. A capacidade e o incentivo dos capitalistas para buscar lucros suplementares ou excedentes na agricultura são inibidos na medida em que a renda possa ser apropriada" (BARTTOMORE, 1988, p. 127).

3 Tradução livre feita pelo autor do texto em francês: "Ainsi, refusant de " donner une définition de la propriété comme d'um rapport indépendant, d'une catégorie à part, d'une idée abstraite et éternelle », Marx n'a pas donné une définition de la propriété, mais plusieurs définitions. C'est par la saisie du concept dans la diversité des significations que lui donne l'histoire, qu'il était possible de dégager une théorie de la propriété, théorie qui n'est pas une définition, mais la théorie des diverses définitions de la propriété et des rapports qui existent entre chacune d'elles" (HÉRICHON, 1970, p. 163-181).

4 "A acumulação primitiva diz respeito às origens históricas do trabalho assalariado, assim como à acumulação nas mãos do capitalista dos recursos necessários para empregá-lo. Trata-se da expropriação violenta de toda uma classe de pessoas do controle sobre os meios de produção, primeiro por meio de ações ilegais e, por fim, como a lei de cercamento na Inglaterra, pela ação do Estado" (HARVEY, 2013, p. 279-280).

5 "Uma vez que as relações de produção pré-capitalistas são predominantemente agrícolas, dispondo os camponeses dos principais meios de produção, como a terra, o capitalismo só se pode afirmar esbulhando os camponeses de sua terra. Assim sendo, as origens do capitalismo encontram-se na transformação das relações de produção no campo. A separação entre os camponeses 
e a terra é o manancial de onde provêm os trabalhadores assalariados, tanto para o capital agrícola como para a indústria" (ABBAGNANO, 1998, p. 15).

6 "Uma vez que o valor nasce do trabalho e outra coisa não é senão trabalho materializado, se o empresário retribuísse ao assalariado o valor total produzido pelo seu trabalho, não existiria o fenômeno puramente capitalista do dinheiro que gera dinheiro. Mas como o empresário não retribui ao assalariado aquilo que corresponde ao valor por ele produzido, mas apenas o custo da sua força de trabalho (o suficiente para produzi-la, o mínimo vital), temos o fenômeno da mais-valia que é a parte do valor produzido pelo trabalhador assalariado da qual o capitalista de apodera" (ABBAGNANO, 1998, p. 637-638).

\section{Referências}

ABBAGNANO, Nicola. Dicionário de Filosofia. São Paulo: Martins Fontes, 1998.

ALVES, Antônio José Lopes. Propriedade Privada e Liberdade Em Hegel e Marx. Revista Intuitio, Porto Alegre, v. 1, n. 2, nov. 2008.

ANDRADE, Diogo de Calasans Melo. O Princípio da Função Social da Propriedade. São Paulo: Letras Jurídicas, 2014.

BARTTOMORE, Tom. Dicionário do Pensamento Marxista. Rio de Janeiro: Zahar, 1988.

COMPARATO, Fábio Konder. Direito e deveres fundamentais em matéria de propriedade. Revista CEJ, v. 1, n. 3, set./dez. 1997.

ENGELS, Friedrich. A Origem da Família da Propriedade Privada e do Estado. Tradução de Ruth M Klaus. 4. ed. São Paulo: Centauro, 2012.

MARX, Karl. Os despossuídos: debates sobre a lei referente ao furto de madeira. Tradução de Nélio Schneider, Daniel Bensaid e Mariana Echalar. São Paulo: Boitempo, 2017.

. Manuscritos econômico-filosóficos e outros textos escolhidos. Tradução de Jesus Raineri. São Paulo: Boitempo, 2004.
- O Capital: Crítica da Economia Política. Tradução de Regis Barbosa e Flávio R. Kothe. Livro primeiro. Tomo I. Cap. I. São Paulo: Nova Cultural, 1996.

HARVEY, David. Para entender o capital. Tradução de Rubens Enderle. São Paulo: Boitempo, 2013.

HÉRICHON, Emmanuel. Le concept de propriétédans la pensée de Karl Marx. In: L'Homme et la société, N. 17, 1970. Sociologie et idéologie: marxisme et marxologie. p. 163-181.

HOBSBAWM, Eric J. Ecos da Marselhesa: dois séculos reveem a Revolução Francesa. Tradução de Maria Celia Paoli. São Paulo: Companhia das Letras, 1996.

MARTINS, José de Souza. O cativeiro da terra. 9. ed. São Paulo: Contexto, 2015.

MEKSENAS, Paulo. Introdução ao conceito de propriedade nos Manuscritos Econômicos e Filosóficos de Marx. Revista Espaço Acadêmico, ano VIII, n. 86, jul. 2008.

NAVES, Márcio Bilharinho. A Questão do Direito em Marx. São Paulo: Outras Expressões; Dobra Universitária, 2014.

THOMPSON, Edward Palmer. Costumes em comum. Tradução de Rosaura Eichemberg. São Paulo: Companhia das Letras, 1998.

PENHAVEL, Pedro Felix Carmo. Capitalismo avançado e acumulação primitiva: a urbanização por despossessão. Anais do II Seminário de Pesquisa da Faculdade de Ciências Sociais. Nov. 2011.

ROLNIK, Raquel. Guerra dos Lugares: a colonização da terra e da moradia na era das finanças. São Paulo: Boitempo, 2015.

TIGAR, Michael E.; LEVY, Madeleine R. O Direito e a Ascensão do Capitalismo. Tradução de Ruy Jungmann. Rio de Janeiro: Zahar, 1977. 